\title{
MATHEMATICAL APPROACH FOR PILOT-SCALE EXPERIMENT SETUP ON BIOGAS PRODUCTION
}

\author{
ADRIAN EUGEN CIOABLĂa ${ }^{a}$ MĂDĂLINA IVANOVICI $I^{\mathrm{b}, \mathrm{c}}$, \\ GABRIELA-ALINA DUMITREL ${ }^{d,},{ }^{,}$, LAURENȚIU-VALENTIN ORDODI ${ }^{d}$, \\ DELIA-GABRIELA CĂLINOIU ${ }^{\mathrm{e}}$, GAVRILĂ TRIF-TORDAI ${ }^{a}$, \\ VASILE PODE ${ }^{\mathrm{d}}$
}

\begin{abstract}
In this work, pilot scale experiments were carried to evaluate the biogas production through anaerobic co-digestion for two different mixtures of feedstock based on agricultural biomass and agricultural waste. The first mixture consisted of degraded row barley and wastewater from treatment plant and the second mixture contained wheat, corn grains and shell sunflower seeds with wastewater from treatment plant. The temperature, $\mathrm{pH}$, pressure and the amount of the produced biogas were daily monitored for 26 days and the results of the two experimental charges were assessed and compared using statistical analysis: the box plot method and summary statistics. The latter feedstock mixture showed a better production of biogas for which the mean value of produced biogas amount is $18.43 \mathrm{~m}^{3}$, whereas the mean value of the biogas generated for the former feedstock mixture was $14.95 \mathrm{~m}^{3}$.
\end{abstract}

Keywords: biogas production, agricultural biomass, pilot scale, co-digestion, statistics

\section{INTRODUCTION}

Anaerobic digestion is reported to be one of the most exploited and attractive technologies for renewable energy production by conversion of biomass. Biogas production by anaerobic digestion is a versatile process,

\footnotetext{
a Politehnica University of Timisoara, Faculty of Mechanical Engineering, 1 Mihai Viteazu blvd., RO-300222, Timisoara, Romania

b Politehnica University of Timisoara, 2 Piata Victoriei, RO-300006, Timisoara, Romania

c National Institute for Research and Development in Electrochemistry and Condensed Matter, 144 Aurel Paunescu Podeanu str., RO-300569, Timisoara, Romania

d Politehnica University of Timisoara, Faculty of Industrial Chemistry and Environmental Engineering, 6 Vasile Parvan blvd., RO-300223, Timisoara, Romania

e Politehnica University of Timisoara, Faculty of Electrical and Power Engineering, 2 Vasile Parvan blvd., RO-300223, Timisoara, Romania

* Corresponding author: alina.dumitrel@upt.ro
} 
worldwide used at small and large scale for heat and electricity generation and also as a transport fuel [1,2]. It can be applied for a large variety of feedstock: energy crops, organic fraction from municipal solid waste, commercial and industrial sector waste, agricultural waste including animal manure and slurry and crop and forest residue, algae, sewage sludge [2-4]. In European Union, approximately half of the biogas production comes from energy crops (primary maize), followed by landfill, organic waste, sewage sludge and manure [5].

In order to avoid the competition with food chain production, the usage of energy crop as a feedstock for biogas production has been discouraged [6]. As well, due to the environmental and economical reasons, the developments in this field have focused on biogas production from biodegradable waste [7].

The waste generated in the agriculture sector is considered a promising organic matter for biogas production. Different types of waste are produced depending on the agricultural activities, therefore it can be distinguished crop and food processing waste (such as maize, sugarcane bagasse, corn stalks, fruits, vegetables), waste from farm animals (manure, organic residue from slaughterhouse, wastewater containing urine) and also toxic substances coming from crop treatments (pesticides, insecticides, etc.) $[8,9]$. The interest in energy recovery by exploitation of agricultural waste has led to numerous research activities related to efficiency of biogas generation from crops residues. Hence, among the agro-waste feedstock subjected to anaerobic digestion, there may be mentioned: rice straw, maize straw, barley, wheat, corn silage, meadow grass, ryegrass, switchgrass, rotten fruits and vegetables with a methane yield ranging from 0.122 to $0.388 \mathrm{~m}^{3}$ per $\mathrm{kg}$ of volatile solids [10-14].

Still, anaerobic digestion of a single substrate results in low amounts of obtained biogas. In this sense, co-digestion is one of the several approaches for enhancement of biogas production technology. In the anaerobic co-digestion process, two or more organic substrates are used simultaneously as feedstock for biogas generation. The advantages of co-digestion referred in literature are: a better ratio of carbon to nitrogen elements, an improvement of $\mathrm{pH}$ values variation during the process, close to the optimal $\mathrm{pH}$ range, higher methane yields (up to $200 \%$ depending on the process operating parameters) which implies also the increasing of biogas reactors economics, synergetic effect caused by mixture of different substrates involved in the process [8,15-17]. If not chosen properly, due to the diversity and characteristics of feedstock, the combination of various substrates may lead to process instability. Experimental models are frequently used in order to estimates the biogas quality and quantity as a function of process parameters $[18,19]$, while also determining the potential calculus errors due to experimental approach [20]. Pilot-scale plants are required in order to evaluate the feasibility of the co-digestion process for specific substrates [21]. 


\section{MATHEMATICAL APPROACH FOR PILOT-SCALE EXPERIMENT SETUP ON \\ BIOGAS PRODUCTION}

In this study, a pilot scale experimental setup was used for evaluation of biogas production by anaerobic co-digestion of different agricultural biomass (row barley, wheat, corn grains and shell sunflower) with wastewater from treatment plant. The process performances are assessed by statistical interpretation of the data using summary statistics and box plot method.

\section{RESULTS AND DISCUSSION}

The paper focuses on statistical analysis done on the amount of biogas resulted from the anaerobic fermentation. The types of agricultural biomass used, in the biogas pilot plant at Politehnica University Timisoara, are: i) reactor 1 (R1) - degraded two row barley and wastewater from treatment plants, ii) reactor 2 (R2) - $40 \%$ wheat and $40 \%$ corn grains plus $20 \%$ shell sunflower seeds and wastewater from treatment plant.

Fig. 1 shows the results of daily biogas production for each reactor, which was taken on a daily, over the course of July. Here are represented the most important parameters characterizing the fermentation process. The variation of biogas production, in $\mathrm{m}^{3}$, can be seen in Fig. $1 \mathrm{a}$.
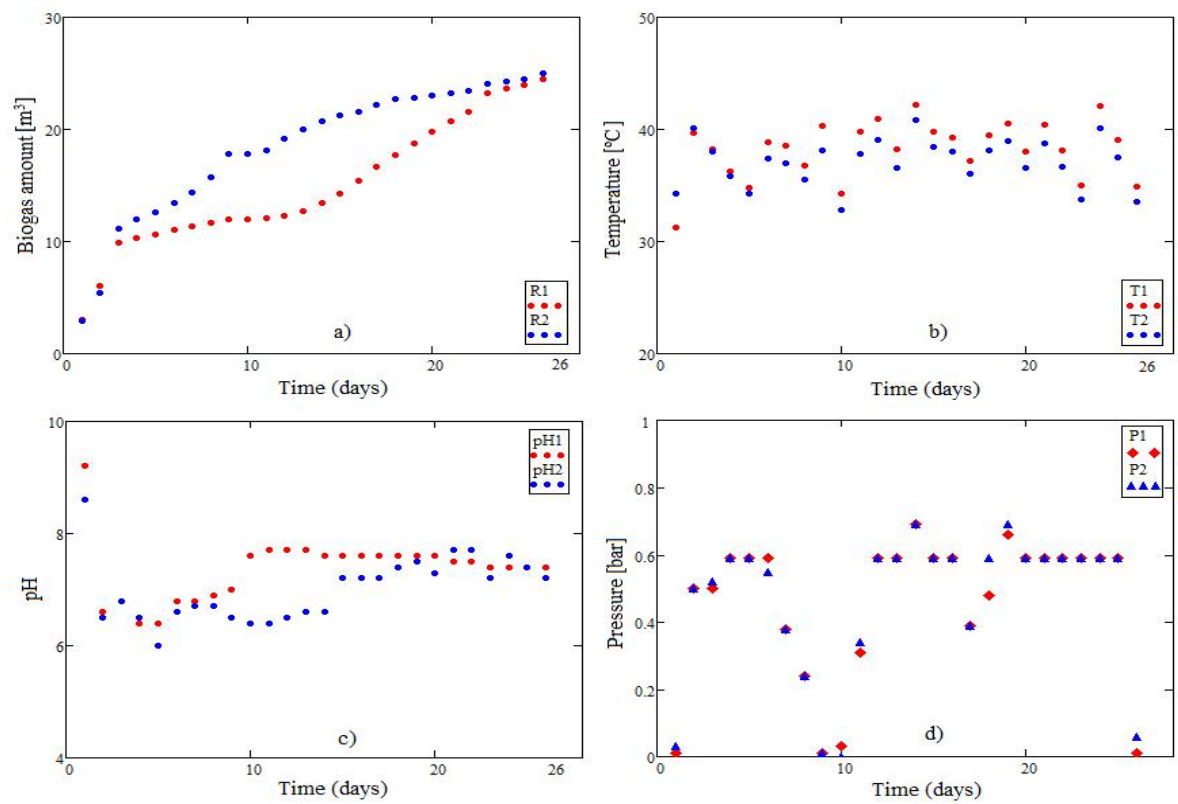

Figure 1. The daily biogas production in fermentation process for 26 days, in July. a) biogas production, expressed in $\mathrm{m}^{3}$; b) temperature, in ${ }^{\circ} \mathrm{C}$; c) $\mathrm{pH}$; d) pressure, in bar.

Parameters that have index 1 are specific for reactor 1 , and index 2 for reactor 2 . 
Also, in Fig.1b and Fig.1c are shown the daily values measured for temperature and $\mathrm{pH}$ respectively. It was observed that throughout the duration of the digestion process, the temperature ranges from 31.3 to $42.2^{\circ} \mathrm{C}$ in the first reactor and in the second reactor is between $32.8^{\circ} \mathrm{C}$ and $40.8^{\circ} \mathrm{C}$ respectively. In this study, the variation of temperatures recorded from the two reactors had the same trend.

An important role related to microbial life growth during fermentation is played by the $\mathrm{pH}$, the anaerobes prefer a $\mathrm{pH}$ close to optimum values, in the range of $6.6-7.3$, and the neutral $\mathrm{pH}$ is best suitable for biogas production, since most of the methanogens grow at the $\mathrm{pH}$ range of $6.5-7.5$. In the first day the $\mathrm{pH}$ values for the both reactor was strongly alkaline, after that the value was adjusted in the range 6 and 7.8 (see Fig.1c).

The $\mathrm{pH}$ graphical representation is not similar, after 10 days until the end of the measurement period, in first reactor the values is in range 7.4 and 7.6, while in the second reactor the variation is higher between 6.4 and 7.7.

The $\mathrm{CH}_{4}$ percentage on 3 and 11 days is $23 \%$ for the both reactors and $77 \%$ in $\mathrm{R} 1$, and $80 \%$ in $\mathrm{R} 2$ respectively. Also, the $\mathrm{CO}_{2}$ percentage on 3 and 11 days is $77 \%$ for the both reactors and $23 \%$ in R1, and $20 \%$ in R2 respectively. Another important parameter in the fermentation process is the pressure, which is represented in Fig. 1d. Note that the points that mark the readings of pressure, expressed in bar, almost coincide.

The box plot from Fig. 2 allows to visualize and compare the distribution of data based on the five numbers summary: minimum, first quartile, median, third quartile, and maximum.

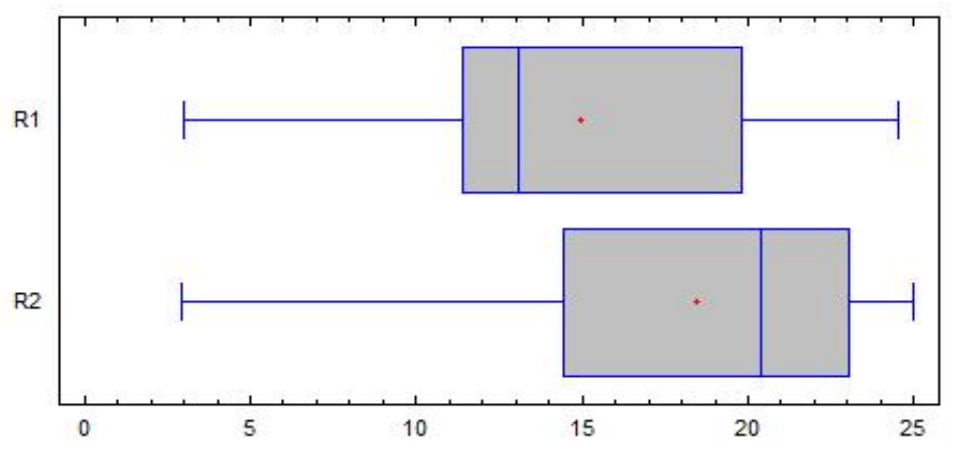

Figure 2. Variation of biogas production in anaerobic fermentation - box plot.

The plots show that the distribution between the data points is different. The median of the values is depicted as a line splitting the box in half. Also, the mean is represented by a red plus. In case of R1 the mean is positioned 
after median, and before the median for $\mathrm{R} 2$, respectively. The interquartile range (IRQ) of a box plot is a visualization of the range from the first quantile to the third quantile, which is 8.41 for $R 1$, and 8.59 for R2, respectively. In IRQ are $50 \%$ from measured data of biogas production.

Table 1 and Table 2 show summary statistics of data measured from amount of biogas production, pressure, $\mathrm{pH}$ and temperature by the both reactors. The mean of amount of biogas production is $14.95 \mathrm{~m}^{3}$ for $\mathrm{R} 1$ and $18.43 \mathrm{~m}^{3}$ for R2. The difference between the amounts of biogas production is given by biomass used for each reactor. Also, the coefficient of variation (defined as the ratio of the standard deviation to the mean) is 1.2 times higher for R1 indicating a larger distribution of values around the mean.

Table 1. Summary statistics for amount of biogas production and the most important parameters in fermentation process from $\mathrm{R} 1$ reactor.

$P$ is pressure and $T$ - temperature.

\begin{tabular}{|c|c|c|c|c|}
\hline & $\left.\mathbf{R} 1 \mathbf{~ m}^{\mathbf{3}}\right]$ & $\mathbf{P}[\mathbf{b a r}]$ & $\mathbf{p H}$ & $\mathbf{T}\left[{ }^{\circ} \mathbf{C}\right]$ \\
\hline Mean & 14.947 & 0.457 & 7.361 & 38.235 \\
\hline Standard deviation & 5.691 & 0.218 & 0.564 & 2.583 \\
\hline Coefficient of variation & $38.07 \%$ & $47.76 \%$ & $7.66 \%$ & $6.76 \%$ \\
\hline Minimum & 3 & 0.01 & 6.4 & 31.3 \\
\hline Maximum & 24.524 & 0.69 & 9.2 & 42.2 \\
\hline Range & 21.524 & 0.68 & 2.8 & 10.9 \\
\hline Stnd. skewness & 0.266 & -2.673 & 1.786 & -1.740 \\
\hline Stnd. kurtosis & -0.601 & 0.302 & 3.756 & 0.690 \\
\hline
\end{tabular}

Table 2. Summary statistics for amount of biogas production and the most important parameters in fermentation process from $\mathrm{R} 2$ reactor.

$P$ is pressure and $T$ - temperature.

\begin{tabular}{|c|c|c|c|c|}
\hline & $\mathbf{R 2}\left[\mathbf{m}^{\mathbf{3}}\right]$ & $\mathbf{P}[\mathbf{b a r}]$ & $\mathbf{p H}$ & $\mathbf{T}\left[{ }^{\circ} \mathbf{C}\right]$ \\
\hline Mean & 18.436 & 0.464 & 7.0 & 37.081 \\
\hline Standard deviation & 5.937 & 0.216 & 0.572 & 2.120 \\
\hline Coefficient of variation & $32.20 \%$ & $46.63 \%$ & $8.17 \%$ & $5.72 \%$ \\
\hline Minimum & 2.962 & 0.0 & 6.0 & 32.8 \\
\hline Maximum & 24.963 & 0.69 & 8.6 & 40.8 \\
\hline Range & 22.001 & 0.69 & 2.6 & 8.0 \\
\hline Stnd. skewness & -2.368 & -2.723 & 1.510 & -0.728 \\
\hline Stnd. kurtosis & 0.766 & 0.386 & 0.865 & -0.524 \\
\hline
\end{tabular}

Of particular interest here are the standardized skewness and standardized kurtosis, which can be used to determine whether the samples come from normal distributions. Values of these statistics outside the range 
of -2 to +2 indicate significant departures from normality, which would tend to invalidate the tests which compare the standard deviations. In this case, pressure for R1 and R2 has a standardized skewness value outside the normal range. Also, the biogas production in $\mathrm{R} 2$ has standardized skewness - 2.36, which value outside the normal range. On the other hand, standardized kurtosis value of pressure from R1 is outside the normal range. With few exceptions discussed above, both standardized kurtosis values are within the range expected.

\section{CONCLUSIONS}

The present paper underlines the usage of agricultural type biomass in fermentation processes from the point of view of using a renewable energy carrier with impact on local energetic autonomy.

The process was treated from different points: experimental and mathematical in order to determine the possible errors of the developed method of monitoring.

From the obtained data, the batch containing the cereal recipe had the greater biogas production and the mean standard deviation resulted from calculation is acceptable in terms of possible errors that could appear from a measuring stand. Further testing and experimental approach is still needed in order to better determine the process details and to accurately correlate them with the mathematical approach.

\section{EXPERIMENTAL SECTION}

The used materials that were used are: for reactor $1(\mathrm{R} 1)$ - degraded two row barley and wastewater from treatment plant and for reactor 2 (R2) $40 \%$ wheat and $40 \%$ corn grains plus $20 \%$ shell sunflower seeds and wastewater from treatment plant. The fermentation process was monitored for 26 days, recording the following parameters for the two reactors: pressure (SCP01 pressure sensors with an accuracy of $\pm 0.1 \%$ ), $\mathrm{pH}$ (BL931700 pH Mini Controller with an accuracy of \pm 0.02 ), temperature (thermocouple $K$ type with an accuracy of $\pm 0.4 \%$ ) and biogas production (mechanical gas counter with diaphragms, $\mathrm{G} 1$ model, accuracy class 1.5). Also, during the process there were observed the produced biogas quantities and quality in terms of methane and carbon dioxide concentrations in the produced biogas. The results were obtained using a DELTA SIV gas analyzer with data accuracy of $\pm 5 \%$ by volume. The materials were initially prepared by grinding to an average value of 1-2 mm for each chosen type. The $\mathrm{pH}$ was initially corrected by using caustic soda in 
the first days of the process in order to have an overall value in the domain $6.5-7.5$. The temperature was kept in the domain of $36-39^{\circ} \mathrm{C}$ during the entire process. The materials were used in batch type reactors and measurements were taken on daily basis.

\section{REFERENCES}

1. L. C. Grangeiro; S. G. Coêlho de Almeida; B. Sampaio de Mello; L. T. Fuess; A. Sarti; K. J. Dussán; New trends in biogas production and utilization. In Sustainable Bioenergy: Advances and Impacts, 1st ed.; M. Rai, A. P. Ingle Eds.; Elsevier, 2019, Chapter 7, pp. 199-233

2. S. Achinas; V. Achinas; G. J. W. Euverink; Engineering, 2017, 3, 229-307

3. P. Baltrènas; A. Misevičius; J. Environ. Health Sci. Eng., 2015, 13

4. M. M. Kabir; K. Rajendran; M. J. Taherzadeh; I. Sárvári Horváth; Bioresour. Technol., 2015, 178, 201-208

5. B. Kampman; C. Leguijt; T. Scholten; J. Tallat-Kelpsaite; R. Brückmann; G. Maroulis; J. P. Lesschen; K. Meesters; N. Sikirica; B. Elbersen; Optimal use of biogas from waste streams. An assessment of the potential of biogas from digestion in the EU beyond 2020, March 2017. Accessed on: June 29, 2019. [Online]. Available at: https://ec.europa.eu/energy/en/studies/optimal-use-biogas-waste-streamsassessment-potential-biogas-digestion-eu-beyond-2020

6. Directive (EU) 2015/1513 of the European Parliament and of the Council Amending Directive 98/70/EC Relating to the Quality of Petrol and Diesel Fuels and Amending Directive 2009/28/EC on the Promotion of the Use of Energy from Renewable Sources (2015), Official Journal of the European Union L239, p. 1-29

7. K. C. Surendra; D. Takara; A. G. Hashimoto; S. K. Khanal; Renew. Sust. Energ. Rev., 2014, 31, 846-859

8. G. Merlin; H. Boileau; Anaerobic Digestion of Agricultural Waste: State of the Art and Future Trends. In Anaerobic Digestion: Types, Processes and Environmental Impact, A. Torrles Eds.; Nova Science Publishers, New York, USA, 2013

9. F. O. Obi; B. O. Ugwuishiwu; J. N. Nwakaire; NIJOTECH, 2016, 35, 957-964

10. G. V. Nallathambi; Biomass Bioenerg., 2004, 26, 389-99

11. M. M. Søndergaard; I. A. Fotidis; A. Kovalovszki; I. Angelidaki; Energ. Fuel., 2015, 29, 8088-8094

12. R. A. Labatut; L. T. Angenent; N.R. Scott; Bioresour. Technol., 2011, 102, 2255 2264

13. P. Tsapekos; P. G. Kougias; I. Angelidaki; Energ. Fuel., 2015, 29, 4005-4010

14. Y. Li; R. Zhang; G. Liu; C. Chen; Y. He; X. Liu; Bioresour. Technol., 2013, 149, 565-569

15. K. Hagos; J. Zong; D. Li; C. Liu; X. Lu; Renew. Sust. Energ. Rev., 2017, 76, 14851496

16. T. Dias; R. Fragoso; E. Duarte; Bioresour. Technol., 2014, 164, 420-423 
ADRIAN EUGEN CIOABLĂ, MĂDĂLINA IVANOVICI, GABRIELA-ALINA DUMITREL, LAURENȚIU-VALENTIN ORDODI, DELIA-GABRIELA CĂLINOIU, GAVRILĂ TRIF-TORDAI, VASILE PODE

17. J. H. Ebner; R. A. Labatut; J. S. Lodge; A. A. Williamsona; T. A. Trabold; Waste. Manage., 2016, 52, 286-294

18. A.E. Cioabla; G.-A. Dumitrel; I. Ionel; Rev. Chim. - Bucharest, 2017, 68(11), 2614-2617

19. G.-A. Dumitrel; A.E. Cioabla; I. Ionel; L.A. Varga; Rev. Chim. - Bucharest, 2017, 68(6), 1294-1297

20. A.E. Cioablă; G.-A. Dumitrel; A.-M. Pana; F. Popescu; D. Lelea; A. Tenchea; L. I. Dungan; VIII International Conference Industrial Engineering and Environmental Protection 2018 (IIZS 2018) October 11-12th, 2018, Zrenjanin, Serbia, 362-367

21. S. Xie; F. I. Hai; X. Zhan; W. Guo; H. H. Ngo; W. E. Price; L. D. Nghiem; Bioresour. Technol., 2016, 222, 498-512 